\title{
Antioxidant Activities, Phenolic Contents and Electronic Nose Analysis of Black Garlic
}

\author{
Ozan Emre Eyupoglu (iD**,1
}

${ }^{1}$ Department of Biochemistry, School of Pharmacy, Istanbul Medipol University, 34810, Beykoz-Istanbul/ Turkey

\begin{abstract}
Black garlic is a processed garlic product with a moisture-controlled high temperature heat treatment for a long time. In order to determine the secondary metabolites of black garlics treated in the study, firstly, in vitro antioxidant activities of black garlics purchased from Edovital company, Kastamonu, Turkey were determined, followed by qualitative and quantitative measurement of the phenolic compound content by HPLC and finally the electronic nose analysis of the content of nebulizer vapors in wood vinegar extract of black garlics were done successfully. Chlorogenic acid, vanillic acid, benzoic acid, gallic acid contents in detected 13 phenolic acids were quitely high. All quantitative results were expressed as mg gallic acid equivalent (GAE) per g dry matter of black garlic sample. ABTS and DPPH antioxidant activities were very low according to BHT standart and 2-Methylene-4-pentenal (18\%) and Furfural $(25 \%)$ were detected in high amount with electronic nose in nebulvapor contents of black garlic wood vinegar extract.
\end{abstract}

\section{ARTICLE HISTORY}

Received: January 16, 2019

Revised: May 02, 2019

Accepted: May 11, 2019

\section{KEYWORDS}

Black garlic, Antioxidant activity, Phenolic contents, Electronic nose, HPLC analysis

\section{INTRODUCTION}

Black garlic is a processed state of fresh garlic under high temperature and humidity by the Maillard reaction. D,L-lactic acid, 5-hydroxymethyl-2-furfural, adenosine, uridine, (1S,3S)1-methyl-1,2,3,4-tetrahydro- $\beta$-carboline-3-carboxylic acid, (1R,3S)-1-methyl-1,2,3,4tetrahydro- $\beta$-carboline-3-carboxylic acid, and 2-acetylpyrrole were detected in black garlic ethyl acetate extracts with HPLC coupled with diode array detection analysis and NMR spectrometry [1]. Black garlic has many health-promoting properties: effective in the treatment of colon cancer, effective in the treatment of diabetes, having anti-allergic, anti-inflammatory, antioxidant, anticancer and cardiac protective effects [1-5]. Processed black garlic components are polysaccharides, reducing sugars, proteins, phenolic compounds, organic sulfur compounds and melanoidins [6]. The antioxidant capacity of black garlic is related to polyphenols [7]. Black garlic can prevent the development of atherosclerosis by clearing cholesterol [8]. In black garlic, the content of allicin, which gives a harsh aroma taste, is reduced and allisin in the browning process is transformed into antioxidant compounds such as bioactive alkaloid and

\footnotetext{
${ }^{*}$ CONTACT: Ozan Emre EYUPOGLU $\bigotimes$ oeeyupoglul@medipol.edu.tr $\equiv$ Istanbul Medipol University, School of Pharmacy, Biochemistry Department, Kavacık South Campus, Goztepe Dist. Ataturk Str. No.40, 34810, Beykoz-Istanbul-Turkey
} 
flavonoid compounds [9]. Black garlic have been consumed in extracted form as well as being used widely as an food ingredient including beverages, candy due to sour taste of it [10]. Black garlic whose main volatiling components are organosulfur compounds such as thiosulfinates and sulfur [11]. High antioxidant activity of black garlic have been observed with S-allyl cystein (watersoluble compound) increases by fermentation [12]. In one study, as the concentration of black garlic increased, the DPPH radical clearing ability increased due to increased polyphenol content of treated black garlic [13]. In other study, ABTS scavenging activity was the highest in aged black garlic extract [14]. The aim of this study is finding out of phenolic and antioxidant profile of black garlic. In addition to this, with different method from literature, wood vinegar extract of black garlic converted into vapor phase by nebulizer and these vapors were analyzed to determine of content with electronic nose.

\section{MATERIAL AND METHODS}

\subsection{Procurement of Plant Material and Extraction Process}

Fermentable black Garlics (200 g, stock code: HBV000002R8CH, from Taskopru) were purchased Edovital Company, Kastamonu, Turkey in May, 2018. For extraction of dry black garlic sample powders (30 g, powdered via a blender (Model SHB 3062; Sinbo, Istanbul, Turkey)) were used methanol $(300 \mathrm{~mL})$ solvent with shaker for $24 \mathrm{~h}$ at room temperature. The methanolic extracts of the black garlic were filtered and collected into flasks, before they were dried with rotary evaporator stored at $+4{ }^{\circ} \mathrm{C}$ in refrigerator (Bosch, Germany) until use [15].

\subsection{DPPH (1,1-diphenyl-2-picrylhydrazyl) Radical Scavenging Activity}

DPPH radical scavenging ability was determined with slight modifications of method of Zhang et al. (2011) at $517 \mathrm{~nm}$ by using a spectrophotometer [16]. $1 \mathrm{~mL}$ of $0.1 \mathrm{mM}$ DPPH radical (CAS Number 1898-66-4, 1 g, Sigma-Aldrich) solution prepared in methanol was mixed with $1 \mathrm{~mL}$ of the test sample $(2 \mathrm{mg} / \mathrm{mL}$, methanolic black garlic extract at $2 \mathrm{~h} 6000 \mathrm{rpm}$ (Nuve laboratory technology)) dissolved in $100 \mathrm{mM}$ acetate buffer ( $\mathrm{pH}$ 7.2). The mixture was shaken and left to stand for $20 \mathrm{~min}$ in the dark until spectrophotometric measurement (with double beam UV-Vis spectrophotometer, Schimadzu (190 nm-1100 nm)) and butylated hydroxy toluene (BHT) ( $\geq 99 \%$, Sigma-Aldrich) was used as a positive control.

The half inhibitory concentration $\left(\mathrm{IC}_{50}\right.$ ) (represents the concentration that caused a $50 \%$ inhibition of radical formation) value was used to express the results [16]. IC 50 value (Table 1) was obtained by using DPPH inhibition graph.

\subsection{FRAP (Ferric Reducing Antioxidant Power) Activity}

FRAP assay (is based on electron transfer) was performed by following the method described by Benzie and Straine (1996) [17], with soft modifications (FRAP reagent consist on mixing acetate buffer at $\mathrm{pH}$ 3.6, $10 \mathrm{mM}$ 2,4,6-tripyridyl-S-triazine (TPTZ) ( $\geq 99.0 \%$, HPLC grade, Merck) acidic solution and $20 \mathrm{mM} \mathrm{FeCl}_{3} .6 \mathrm{H}_{2} \mathrm{O}(97 \%, 5 \mathrm{~g}$, Sigma-aldrich, CAS Number: 10025-77-1)). The reaction mixture (FRAP reagent and black garlic methanolic extract (2 mg / $\mathrm{mL})(3: 1)$ ) was then incubated at $37^{\circ} \mathrm{C}$ for 4 min (Nuve laboratory technology, BM 30 water bath). Absorbance was determined at $595 \mathrm{~nm}$ against a blank prepared using distilled water. The result was given as the average Trolox equivalent (TEAC) of 3 repeat measurements [17] (Table 1).

\subsection{CUPRAC (Cupric Ion Reducing Antioxidant Capacity) Assay}

The chromogenic redox reagent, bis (neocuproine) copper (II) chelate for the CUPRAC assay produced a stable and colorful $\mathrm{Cu}$ (I)- neocuproine chelate as a result of the redox reaction with the polyphenols at $\mathrm{pH} 7$. The absorbance of the color was measured at $450 \mathrm{~nm}$. Antioxidant activity was calculated as the average Trolox equivalent (TEAC) of 3 repeat measurements. 
Black garlic methanolic extract $(2 \mathrm{mg} / \mathrm{mL})$ and CUPRAC reagent (1:1) were mixed and measured in $1 \mathrm{~min}$ [18] (Table 1).

\subsection{ABTS (2,2'-azino-bis (3-ethylbenzothiazoline-6-sulphonic acid) Radical Scavenging Activity}

The determination of ABTS radicalic activity was based on the mechanism of Re et al. (1999) [19]. The stock solution of ABTS was mixed in dark bottle by dissolving $0.250 \mathrm{~g}$ of ABTS salt and $0.045 \mathrm{~g} \mathrm{~K}_{2} \mathrm{~S}_{2} \mathrm{O}_{8}$ in $100 \mathrm{~mL}$ of ultra pure water, then it was left in the fridge. The prepared ABTS solution was diluted with ultra pure water by using Milli-Q ${ }^{\circledR}$ IQ 7003/7005 Ultrapure Lab Water System (Merck) and before use it was kept at $25^{\circ} \mathrm{C}$ in darkness for $24 \mathrm{~h}$. To measure the radical scavenging ability $0.05 \mathrm{~mL}$ of the black garlic methanolic extract $(2 \mathrm{mg}$ $/ \mathrm{mL}$ ) was added to $2.5 \mathrm{~mL}$ of a diluted ABTS solution. Absorbance was determined after $5 \mathrm{~min}$ incubation at $734 \mathrm{~nm}$ against water as blank. Butylated hydroxy toluene (BHT) ( $\geq 99 \%$, SigmaAldrich) was used as a positive control. The rate of 50\% inhibition (IC $\left.{ }_{50}\right)$ was calculated [19] (Table 1).

Table 1. Antioxidant activity comparison of black garlic methanolic extract according to four different methods.

\begin{tabular}{cccc}
\hline $\begin{array}{c}\text { DPPH } \\
\left(\mathrm{IC}_{50}\right)\end{array}$ & $\begin{array}{c}\text { ABTS } \\
\left(\mathrm{IC}_{50}\right)\end{array}$ & $\begin{array}{c}\text { FRAP } \\
(\mathrm{TEAC})\end{array}$ & $\begin{array}{c}\text { CUPRAC } \\
(\text { TEAC })\end{array}$ \\
$(\mathrm{mg} / \mathrm{mL})$ & $(\mathrm{mg} / \mathrm{mL})$ & $(\mu \mathrm{M} /$ methanolic extract $(\mathrm{mg}))$ & $(\mu \mathrm{M} /$ methanolic extract $(\mathrm{mg}))$ \\
\hline $0.18 \pm 0.02$ & $0.28 \pm 0.03$ & $42.16 \pm 0.04$ & $56.18 \pm 0.02$
\end{tabular}

${ }^{ \pm} \mathrm{SD}$ : Average Standart Deviation, $95 \%$ confidence interval, critical ratio: $p<0.05$

\subsection{Phenolic Analysis with HPLC}

RP-HPLC-DAD analysis system (Agilent 1100 Technologies, Waldbronn, Germany)of phenolic compounds was combined by using a purospher star reverse phase column $(4.6 \times 250$ $\mathrm{mm}, 5 \mu \mathrm{m})$ (Merck, Germany), on a isocratic program with a solvent system (A: $2 \%$ formic acid in methanol:water [1:1]) at a constant solvent flow rate of $0.7 \mathrm{~mL} . \mathrm{min}^{-1}$ Injection volume was $50 \mu \mathrm{L}$ and analysis time was $40 \mathrm{~min}$. Signals were detected at 235, 240, 253, 265, 280, 295, $312,345 \mathrm{~nm}$ by DAD and at $280 \mathrm{~nm}$ (For the phenolic compounds, maximum absorption) by UV detection. Column temperature has been set at room temperature, $25^{\circ} \mathrm{C} .13$ phenolic components were identified by comparing to standards in black garlic methanolic extract ( $2 \mathrm{mg}$ / mL), qualitatively and quantitatively [20] (Figure 1) (Table 2).

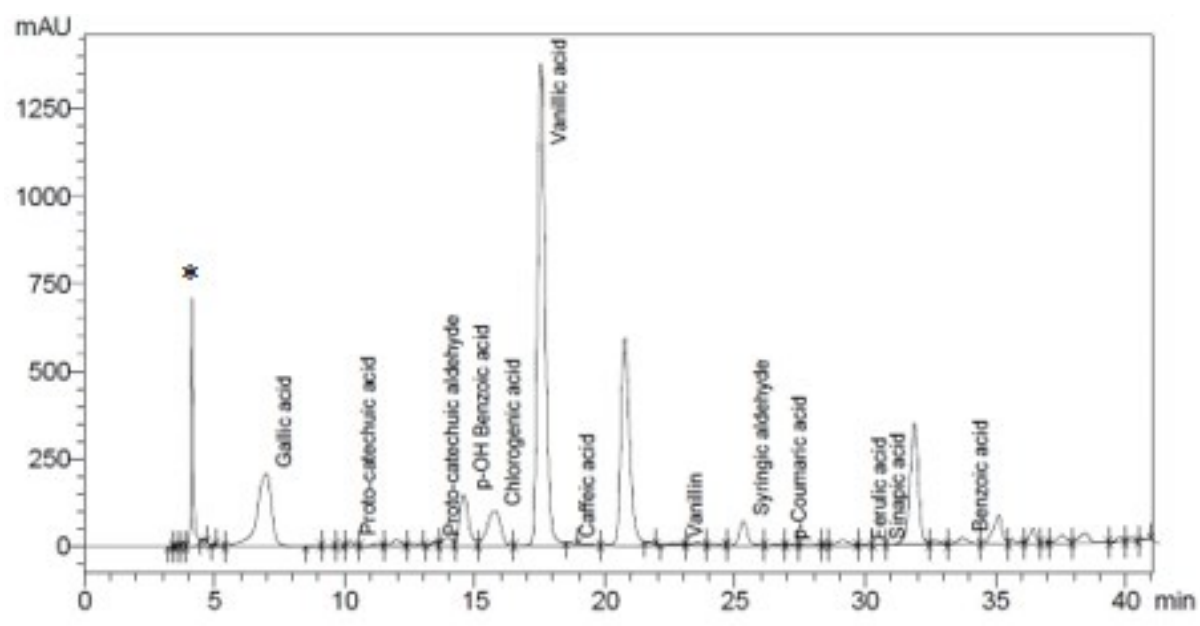

Figure 1. HPLC peak chromatogram of black garlic methanolic extract at $280 \mathrm{~nm}$ 
Table 2. Detected qualitative and quantitative phenolic components of black garlic methanolic extract with HPLC at $280 \mathrm{~nm}\left({ }^{ \pm} \mathrm{SD}\right.$ : Average Standart Deviation, 95\% confidence interval, critical ratio: $\left.p<0.05\right)$

\begin{tabular}{ccccc}
\hline Number & Phenolic Component Name & Retention Time & \% Area & Concentration $(\mathrm{mg} / \mathrm{L})$ \\
\hline$*$ & Unknown & 4.15 & 0.01 & $0.1 \pm 0.01$ \\
\hline 1 & Gallic acid & 6.98 & 18.32 & $172.14 \pm 0.03$ \\
\hline 2 & Proto-catechuic acid & 10.22 & 0.49 & $4.89 \pm 0.02$ \\
\hline 3 & Proto-catechuic aldehyde & 13.41 & 0.20 & $1.11 \pm 0.04$ \\
\hline 4 & $p$-OH Benzoic acid & 14.57 & 7.48 & $94.62 \pm 0.02$ \\
\hline 5 & Chlorogenic acid & 15.77 & 7.69 & $183.08 \pm 0.03$ \\
\hline 6 & Vanillic acid & 17.54 & 60.97 & $750.95 \pm 0.01$ \\
\hline 7 & Caffeic acid & 18.63 & 0.07 & $0.92 \pm 0.03$ \\
\hline 8 & Vanillin & 22.77 & 0.36 & $2.88 \pm 0.01$ \\
\hline 9 & Syringic aldehyde & 25.31 & 3.10 & $95.27 \pm 0.03$ \\
\hline 10 & $p$-Coumaric acid & 26.76 & 0.16 & $1.50 \pm 0.01$ \\
\hline 11 & Ferulic acid & 29.84 & 0.06 & $1.24 \pm 0.04$ \\
\hline 12 & Sinapic acid & 30.53 & 0.01 & $0.09 \pm 0.01$ \\
\hline 13 & Benzoic acid & 33.73 & 1.10 & $223.72 \pm 0.03$ \\
\hline
\end{tabular}

\subsection{Electronic Nose Analysis of Nebulizer Vapors of Black Garlic Wood Vinegar} Extraction Oils

Wood vinegar $(250 \mathrm{~mL})$, which is a kind of dark brown liquid produced by slow pyrolysis of plant biomass, was purchased from Tu Hong Biotech Co., Ltd, Hebei, China (Mainland) and was used for clevenger distillated extraction (Sesim Kimya Laboratuvar, Ankara, Turkey) method of black garlic (30 g) powdered via a blender (Model SHB 3062; Sinbo, Istanbul, Turkey). Collected extraction oils of black garlic were placed in the chamber of nebulizer device (particle size $<4 \mu \mathrm{m}$, Bayer company, Germany). Components analysis of obtained nebulous vapors were realized with electronic nose (PERES foodsniffer (Swiss Technology)) including volatile organic compound sensors combined smartphone (Samsung Galaxy S5 (Seoul, South Korea)) network library in a short time (120 second) [21, 22] (Figure 2).

\subsection{Statistical analysis}

All qualitative and quantitative statistical analysis were reported significantly $(p<0.05)$ with average standard deviation of 3 repeated measurements. Statistical analysis was carried out by using SPSS Version 21.0 software program and Microsoft Excel (Microsoft Office Corporation, 2010, Redmond, Washington).

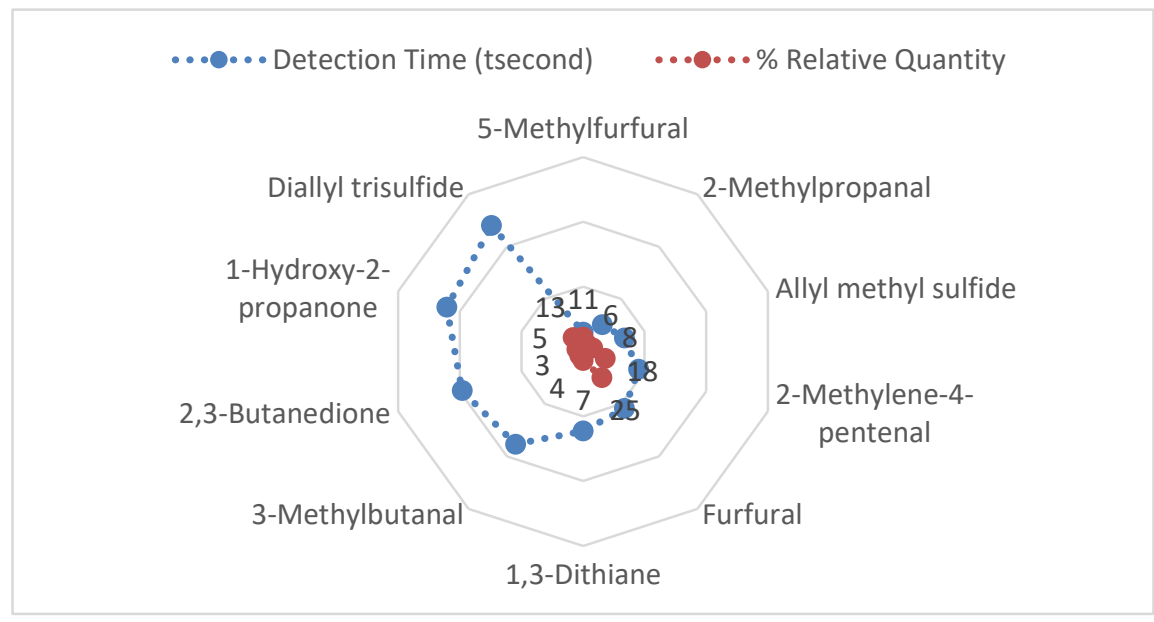

Figure 2. Volatile organic compounds detected with electronic nose 


\section{RESULTS and DISCUSSION}

In one study, DPPH radical clearance of black garlic ethyl acetate extract was $30 \%$ and was equivalent to $5 \mathrm{mg} / \mathrm{mL}$ gallic acid [1]. In another study, black garlic contained many organic acids occurring in nature. Lactic acid was the main organic acid in the black garlic detected in liquid analysis [23]. Therefore, lactic acid may be responsible for unique taste. Total phenolic content in black garlic was increased by about four to 10 times compared to white garlic. Hydroxycinnamic acid derivatives were found to be the major phenolic acids of black garlic at different processing stages [24].

In the other study, malondialdehyde content in black garlic groups at 20 and $40 \mathrm{mg} / \mathrm{kg}$ animal study doses significantly was reduced $(p<0.05)$. In addition to this, Serum superoxide dismutase activities which are showing the effectiveness of antioxidant system in black garlic groups at 20 and $40 \mathrm{mg} / \mathrm{kg}$ animal study doses were significantly higher $(p>0.05)$ [25]. Table 1 antioxidant activity data in this study support this. On the other hand, in volatile components analysis of black garlic, the main sulfur volatiles in the black garlic exhibited an inverse behavior throughout the heating. While the concentration on plant volatiles decreased throughout the warming, the volatile and roasted aroma volatile concentrations increased [26]. In the HPLC profile analysis of free, soluble esters and glycosylated phenolic acids, transhydroxycinnamic acids (caffeic, $p$-coumaric, ferulic and sinapic) in garlic were shown to be twice as high as onions [27]. In this fence, because of the fact that contents of phenolic acids and trans-hydroxycinnamic acids of black garlic were valuable for responsible about antioxidant activity, HPLC phenolic peak profiles were examined in this study.

Electronic nose method is a new trend for volatile content analysis as an alternative to GC-MS. For showing heat process effect on garlics, in a study, electronic nose was used [28]. The electronic nose's (have six sensors) spider radar graph analysis values showed that raw and heat-treated garlic's odour component characteristics were different [28].

In this study, ABTS and DPPH with CUPRAC and FRAP antioxidant activity results of black garlic methanolic extract supported each other in addition to this, DPPH activity was more effective to show the radical scavenging capacity of high antioxidative components than ABTS with increasing percentage of negative slope and CUPRAC activity was also more effective than FRAP about black garlic methanolic extract. Because copper ions were more effective linked to phenolic content from iron ions according to their reduction potentials about antioxidant capacity with positive slope in proportion to the increasing spectrophotometric color intensity (Table 1).

In a study the FRAP value in Taşköprü black garlic $\left(640.76 \pm 86.98 \mu \mathrm{mol}^{-1} \mathrm{~g}^{-1}\right)$ slightly decreased from FRAP value of black garlic in Chinese type (678.20 $\left.777.56 \mu \mathrm{mol}^{-\mathrm{g}^{-1}}\right)$ [29] but in this study, FRAP value of black garlic $(42.16 \pm 0.04 \mu \mathrm{M} / \mathrm{mg})$ was found and this value was quitely high per gram (Table 1). In the other study, The $\mathrm{IC}_{50}$ value of polyphenol extracted from black garlic for DPPH radical inhibition was $140.79 \mu \mathrm{g} / \mathrm{mL}$ [25] but in this study, the $\mathrm{IC}_{50}$ value of black garlic methanolic extract for DPPH r radical inhibition was found as $180 \mu \mathrm{g} / \mathrm{mL}$ (Table 1). The reason for this is that the total content of black garlic including flavonoid and sugar groups decreases the antioxidant activity. In an another study, n-hexane, dichloromethane, ethyl acetate, n-butanol and water extracts of black garlic in different polarities were used to isolate the active ingredients (total polyphenol content) [30]. In the $\mathrm{DPPH}$-radical scavenging and iron reducing power antioxidant activity tests, the aqueous extract of black garlic was more effective [30]. Therefore, the methanolic extract form closest to the polarity of the water was preferred in this study. In the same study, DPPH radical scavenging activity of the aquatical extract of black garlic was high at a concentration of 0.6 $\mathrm{mg} / \mathrm{mL}$ and concentrations below $0.2 \mathrm{mg} / \mathrm{mL}$ were not studied [30]. The DPPH radical scavenging activity of black garlic was measured as $0.18 \pm 0.02$ in this study (Table 1), with the 
idea that different solvent extracts (such as methanol) may exhibit better activity if these concentrations are studied. ABTS radical scavenging activity was higher in hexane, chloroform and ethyl acetate fractions of black garlic and reducing power was also significantly lower in butanol and water fraction (its polarity is close to methanol) [31] as opposite that ABTS radical scavenging activity was high in methanolic extract of black garlic in this study (Table 1).

While in a study, in phenolic analysis with HPLC, coumaric acid was the main ingredient in black garlic residue [32], in this study, in phenolic analysis with HPLC, from detected 13 components at $280 \mathrm{~nm}$, vanillic acid $(60,97 \%$ peak area) was in the foreground as main flavor component of black garlic. Gallic acid (18,32\% peak area), chlorogenic acid (7,69 \% peak area) and $p$-OH Benzoic acid (7,48 \% peak area) with vanillic acid (60,97\% peak area) formed the major components of total phenolic content (Table 2) (Figure 1).

In the HPLC analysis of methanolic extract of black garlic, it is estimated by considering retention time and uv spectrum that the unknown component with asterisk is vitamin $\mathrm{C}$ (Figure 1) (Table 2). 2-Methylene-4-pentenal (18\%), furfural (25\%), diallyl trisulfide (13\%), 5methylfurfural $(11 \%)$ were detected as volatile major organic compounds from 10 components with electronic nose (Figure 2). In other studies, for fermented black garlic according to purple garlic, there was no difference in the amount of ferulic acid, fernented black garlic had high amounts of coumaric acid and caffeic acid and chlorogenic acid decreased significantly [33]. In this study, as opposed to other studies [33], chlorogenic acid was quitely high (Table 2). In other studies, in black garlic, volatile compounds of allyl alcohol and S-alk(en)-yl-L-cysteine derivatives were strongly high and furfural rate was approximetly $4 \%$ of total area of volatile compounds [33] but in this study, furfural compound and its derivatives were strongly high (Figure 2).

\section{CONCLUSION}

Black garlic can be a strong source of antioxidants and phenolic acids and can be used as an alternative fermented food product against oxidative stress. It can also be an aromatic food source as a component of flavor and odor. Most susceptible vitamins especially like ascorbic acid responsible for antioxidant activity can be lost during the heating process for fermented black garlic [33]. In the study, it was found that black garlic had high phenolic acid content especially like vanillic acid $(60,97 \%$ peak area) which have been responsible for sweet aroma from detected 13 components with HPLC-DAD-UV analysis and great antioxidant properties of black garlic were supported by 4 different methods (CUPRAC, FRAP, DPPH, ABTS). The results were statistically significant $(p<0.05)$ (Table 1 and Table 2). Electronic Nose Analysis of Nebulizer Vapors of Black Garlic Wood Vinegar Extraction Oils was applied firstly, in literature. Wood vinegar extraction increased the formation and involvement of furfural derivative compounds (furfural (25\%), 5-methylfurfural (11\%)) in oil phase (Figure 2). Thus, compounds which have low molecular weight and can easily fly were better detected with electronic nose combined nebulizer.

\section{Acknowledgement:}

I did not receive any grant from funding agencies in the public, commercial, or not- for-profit sectors. I thank my dear family for their moral support.

\section{Orcid}

Ozan Emre Eyupoglu (iD) https://orcid.org/0000-0002-4449-0537 


\section{REFERENCES}

[1]. Lu, X., Li, N., Qiao, X., Qiu, Z., and Liu, P. (2017). Composition analysis and antioxidant properties of black garlic extract. J. Food Drug Anal. 25, 340-349, doi: 10.1016/j.jfda.2016.05.011.

[2]. Sun, Y. E., and Wang, W. (2018). Changes in nutritional and bio-functional compounds and antioxidant capacity during black garlic processing. J. Food Sci. Technol. 55, 479488, doi: 10.1007/s13197-017-2956-2

[3]. Dong, M., Yang, G., Liu, H., Liu, X., Lin, S., Sun, D., et al. (2014). Aged blackgarlic extract inhibits ht29 colon cancer cell growth via the pi3k/akt signaling pathway. Biomed. Rep. 2 , 250-254, doi: 10.3892/br.2014.226

[4]. Czompa, A., Szoke, K., Prokisch, J., Gyongyosi, A., Bak, I., Balla, G., et al. (2018). Aged (black) versus raw garlic against ischemia/reperfusion-induced cardiac complications. Int. J. Mol. Sci. 19 (4), 1017, doi: 10.3390/ijms 19041017

[5]. Kimura, S., Tung, Y. C., Pan, M. H., Su, N. S., Lai, Y. J., \& Cheng, K. C. (2017). Black garlic: A critical review of its production, bioactivity, and application. J. Food Drug Anal., 25, 62-70.

[6]. Queiroz, Y.S, Ishimoto, E.Y, Bastos, D.H.M, Sampaio, G.R, Torres, E.A.F.S. (2009). Garlic (Allium sativum L.) and ready-to-eat garlic products: in vitro antioxidant activity. Food Chem., 115, 371-374.

[7]. Choi, I.S, Cha, H.S, Lee, Y.S. (2014). Physicochemical and antioxidant properties of black garlic. Molecules, 19, 16811-16823.

[8]. Seo, Y.J, Gweon, O.C., Im, J., Lee, Y.M., Kang, M.J., Kim, J.I. (2009). Effect of garlic and aged black garlic on hyperglycemia and dyslipidemia in animal model of type 2 diabetes mellitus. J Food Sci Nutr, 14, 1-7.

[9]. Yuan, H., Sun, L., Chen, M., Wang, J. (2016). The comparison of the contents of sugar, Amadori, and Heyns compounds in fresh and black garlic. J Food Sci, 81(7), C1662C1668.

[10]. Bae, S.E., Cho, S.Y., Won, Y.D., Lee, S.H., \& Park, H.J. (2012). A comparative study of the different analytical methods for analysis of S-allyl cysteine in black garlic by HPLC. LWT-Food Sci. Technol. (Campinas), 46, 532-535.

[11]. Molina-Calle, M., Priego-Capote, F., \& Luque de Castro, M. D. (2016). HS-GC/MS volatile profile of different varieties of garlic and their behavior under heating. Anal Bioanal Chem, 408 (14), 3843-3852, doi:10.1007/s00216-016-9477-0

[12]. Amagase, H., et al. (2001). Intake of garlic and its bioactive components. The Journal of Nutrition, 131, 955S-962S.

[13]. Liu J., Zhang G., Cong X., Wen C. (2018). Black Garlic Improves Heart Function in Patients With Coronary Heart Disease by Improving Circulating Antioxidant Levels. Front. Physiol., 9 (1435), 1-11, doi: 10.3389/fphys.2018.01435

[14]. Jeong, Y., Ryu, J., Shin, J.-H., Kang, M., Kang, J., Han, J., \& Kang, D. (2016). Comparison of Anti-Oxidant and Anti-Inflammatory Effects between Fresh and Aged Black Garlic Extracts. Molecules, 21(4), 430, doi:10.3390/molecules21040430

[15]. Chen Y.-C., Kao T.-H., Tseng C.-Y., Chang W.-T., Hsu C.-L. (2014). Methanolic extract of black garlic ameliorates diet-induced obesity via regulating adipogenesis, adipokine biosynthesis, and lipolysis. J Funct Foods, 9, 98-108, doi:10.1016/j.jff.2014.02.019

[16]. Zhang, R.F., Zhang, F.X., Zhang, M.W., Wei, Z.C., Yang, C.Y., Zhang, Y. (2011). Phenolic composition and antioxidant activity in seed coats of 60 Chinese black soybean (Glycine max L. Merr.) varieties. J. Agric. Food Chem., 59, 5935-5944.

[17]. Benzie, I.F.F., and Strain, J.J. (1996). The ferric reducing ability of plasma (FRAP) as a measure of "antioxidant power": The FRAP assay. Anal. Biochem., 239, 70-76. 
[18]. Ozyurek, M., Guclu, K., Apak, R. (2011). The main and modified CUPRAC methods of antioxidant measurement. Trends Anal. Chem., 30 (4), 652-664, doi:10.1016/j.trac.2010.11.016

[19]. Re, R., Pellegrini, N., Proteggente, A., Pannala, A., Yang, M., Rice-Evans, C. (1999). Antioxidant activity applying an improved ABTS radical cation decolorization assay. Free Radic Biol Med., 26 (9-10), 1231-1237.

[20]. Aliyazicioglu, R., Eyupoglu, O.E., Sahin, H., Yildiz, O., Baltas, N. (2013). Phenolic components, antioxidant activity, and mineral analysis of Capparis spinosa L. Afr. J. Biotechnol., 12(47), 6643-6649, doi: 10.5897/AJB2013.13241

[21]. Nimmano, N., Somavarapu, S., Taylor, K.M.G. (2018). Aerosol characterisation of nebulised liposomes co-loaded with erlotinib and genistein using an abbreviated cascade impactor method. Int J Pharmaceut., 542(1-2), 8-17, doi:10.1016/j.ijpharm.2018.02.035

[22]. Rock, F., Barsan, N., Weimar, U. (2008). Electronic Nose: Current Status and Future Trends. Chem Rev., 108(2), 705-725, doi:10.1021/cr068121q

[23]. Lee, H.-H., Kim, I.-J., Kang, S.-T., Kim, Y.-H., Lee, J.-O., Ryu, C.-H. (2010). Development of black garlic yakju and its antioxidant activity. Korean Journal of Food Science and Technology, 42(1), 69-74.

[24]. Kim, J.S, Kang, O.J, Gweon, O.C. (2013). Comparison of phenolic acids and flavonoids in black garlic at different thermal processing steps. J Funct Foods, 51, 80-86.

[25]. Wang, W., Sun, Y. (2016). In vitro and in vivo antioxidant activities of polyphenol extracted from black garlic. Food Sci Technol., 37(4), 681-685, doi:10.1590/1678457X.30816

[26]. Molina-Calle, M., Priego-Capote, F., Luque de Castro, M.D. (2017). Headspace GC-MS volatile profile of black garlic vs fresh garlic: Evolution along fermentation and behavior under heating, Food Sci Technol., 80, 98-105, doi:10.1016/j.lwt.2017.02.010

[27]. Gorinstein, S., Leontowicz, H., Leontowicz, M., Namiesnik, J., Najman, K., Drzewiecki J., et al. (2008). Comparison of the Main Bioactive Compounds and Antioxidant Activities in Garlic and White and Red Onions after Treatment Protocols. J. Agric. Food Chem., 56 (12), 4418-4426, doi:10.1021/jf800038h

[28]. Tamaki, K., Sonoki, S., Tamaki, T., \& Ehara, K. (2008). Measurement of odour after in vitro or in vivo ingestion of raw or heated garlic, using electronic nose, gas chromatography and sensory analysis. Int J Food Sci Technol., 43, 130-139, doi:10.1111/j.1365 2621.2006.01403.x

[29]. Koca, I., Tekguler, B., \& Koca, A. F. (2016). Some physical and chemical characteristics of Taşköprü and Chinese black garlics. Acta Horticulturae, 1143, 221-226, doi:10.17660/actahortic.2016.1143.32

[30]. Chen, Y.-A., Tsai, J.-C., Cheng, K.-C., Liu, K.-F., Chang, C.-K., \& Hsieh, C.-W. (2018). Extracts of black garlic exhibits gastrointestinal motility effect. Food Res Int., 107, 102109, doi:10.1016/j.foodres.2018.02.003

[31]. Shin, J.-H., Lee, H.-G., Kang, M.-J., Lee, S.-J., Sung, N.-J. (2010). Antioxidant activity of solvent fraction from black garlic. J Korean Soc Food Sci Nutr, 39 (7), 933-940, doi:10.3746/jkfn.2010.39.7.933

[32]. Xiong, F, Dai, C-H., Hou, F-R., Zhu P-P., He R-H., and Ma, H-L. (2018). Study on the Ageing Method and Antioxidant Activity of Black Garlic Residues. Czech J. Food Sci., 36(1), 88-97, doi:10.17221/420/2016-CJFS

[33]. Martínez-Casas, L., Lage-Yusty, M., \& López-Hernández, J. (2017). Changes in the Aromatic Profile, Sugars, and Bioactive Compounds When Purple Garlic Is Transformed into Black Garlic. J Agric Food Chem., 65 (49), 10804-10811, doi:10.1021/acs.jafc. $7 b 04423$ 